\title{
Microtron Irradiation Induced Tuning of Dielectric Properties of LDPE-ZnO Nanocomposites
}

\author{
Deepu Thomas, ${ }^{1,2}$ Simon Augustine, ${ }^{2}$ and Jithin Prakash ${ }^{3}$ \\ ${ }^{1}$ Research and Development Centre, Bharathiar University, Coimbatore 641046, India \\ ${ }^{2}$ Research and Post-Graduate Department of Physics, St.Thomas College, Pala, Kottayam 686574, India \\ ${ }^{3}$ Research and Post-Graduate Department of Chemistry, St.Thomas College, Pala, Kottayam 686574, India \\ Correspondence should be addressed to Deepu Thomas; deepuskariankal@gmail.com
}

Received 21 August 2014; Revised 28 January 2015; Accepted 4 February 2015

Academic Editor: Eno E. Ebenso

Copyright (C) 2015 Deepu Thomas et al. This is an open access article distributed under the Creative Commons Attribution License, which permits unrestricted use, distribution, and reproduction in any medium, provided the original work is properly cited.

Low-density polyethylene (LDPE)/ZnO composites were prepared using melt mixing process. ZnO powder with size of $44 \mathrm{~nm}$ was used as reinforcing particle. The electron beam irradiation effects on the dielectric behaviour of a polymer nanocomposite dielectric made of low density polyethylene filled with nanoparticles of $\mathrm{ZnO}$ were studied. The dielectric constant and dielectric loss values were determined by dielectric spectroscopy over a frequency range of $100 \mathrm{KHz}-5 \mathrm{MHz}$ on plane samples of the tested nanodielectrics. The influence of filler concentration, between 2 and 8 wt.\%, and the irradiation effects on the dielectric properties are also discussed in the paper.

\section{Introduction}

The blending of polymer and inorganic fillers is an adaptable method to prepare composites with enhanced performances. The polymers are basically regarded as insulating materials. The electrical properties of this insulating polymer can be altered by adding conductive particles such as carbon nanotube [1-3], metallic filler [4,5], and $\mathrm{ZnO}[6]$. The electrical properties depend upon the structure, shape, size, and concentration of the filler components. The nanoparticles embedded in a polymer matrix have been considered as biosensors for the detection of species in biofluids [7].

It is more cost effective to produce large-scale nanocomposites by means of conventional melt-blending process for industrial applications. The low-density polyethylene (LDPE) is one of the best polymer matrices because it is a thermoplastic widely used for electrical industry sector [8]. The $\mathrm{ZnO}$ nanoparticles have conductivity much higher than LDPE, so the dielectric properties and conductivities of LDPE/ZnO composites are expected to alter with the $\mathrm{ZnO}$ additions. Several methods for processing and characterization have been tested, and some theories and models have been proposed for these materials having a huge nanofillerpolymer interface area which seems to be the main reason responsible for their unique properties [9]. But we are still far from understanding and controlling the phenomena in these materials. The electron beam irradiation of LDPE has been extensively studied in order to reach optimized formulation [10-12]. The formation of free radicals as precursors for the generation of radiolysis product causes the structural modification of polymer matrix. The nanophase in LDPE under electron beam irradiation provides new information on the changes in dielectric properties.

In the present work, the influence of the electron beam irradiation on the dielectric behaviour of low-density polyethylene (LDPE) filled with nanoparticles of $\mathrm{ZnO}$ is analysed. The dielectric constant and dielectric loss values were determined by dielectric spectroscopy (DS) over a frequency range of $100 \mathrm{KHz}-5 \mathrm{MHz}$ before and after irradiation.

\section{Experimental}

The $\mathrm{ZnO}$ nanoparticles were prepared by reverse micelle method. In a typical experiment, first solution was prepared 
by dissolving $8.636 \mathrm{~g} \mathrm{ZnSO}_{4} \cdot 3.603 \mathrm{~g} \mathrm{CH}_{3} \mathrm{COOH}$ and $40 \mathrm{mg}$ SDS as surfactant in $1 \mathrm{dm}^{3}$ of water and sonicated in an ultrasonic bath for 15 minutes. The second solution was prepared by $3.6 \mathrm{~g} \mathrm{NaOH}$ pellets and $25 \mathrm{~mL} 70 \%$ ethanol. Then the first solution was slowly added to the second solution with continuous stirring. The mixture was then microwave irradiated for 10 minutes at $20 \%$ power. The obtained precipitate was filtered by using a Whatman filter (grade 41) and air dried. The white solid product was washed with ethanol six times and with water ten times to remove impurities. Then, the dried precipitate was calcinated at $550^{\circ} \mathrm{C}$ for one hour. The obtained powders were characterized using XRD, FTIR, and SEM. The FTIR spectra were obtained using a SHIMADZU FTIR-8400S, Japan, in the range of $400 \mathrm{~cm}^{-1}$ to $5000 \mathrm{~cm}^{-1}$. Xray diffractograms of $\mathrm{ZnO}$ nanopowders were taken using $\mathrm{GE}$ Inspection Technologies Seifert (PTS 3003), using a copper $\mathrm{k} \alpha$ radiation $(\lambda=1.54 \AA)$. Scanning electron micrographs of $\mathrm{ZnO}$ nanoparticles were obtained by (Philips XL 30) SEM. Low-density polyethylene (LDPE)/ZnO composites loaded with $2 \%, 4 \%$, and $8 \%$ nano- $\mathrm{ZnO}$ particles were prepared by melt mixing process using an internal mixer. The composites were made into thin sheets by compressed moulding using a temperature controlled hydraulic press.

2.1. Electron Irradiation. Specifications of electron beam used for irradiation are as follows: beam energy: $8 \mathrm{MeV}$, beam current: $25-30 \mathrm{~mA}$, beam size: $5 \mathrm{~mm} \times 5 \mathrm{~mm}$, pulse repetition rate: $50 \mathrm{~Hz}$, pulse width: $2.5 \mu \mathrm{s}$, dose rate: $1 \mathrm{kGy} / \mathrm{min}$ (Fricke dosimetry). The sample was kept at a distance of $30 \mathrm{~cm}$ from the target. The (LDPE)/ZnO composites were irradiated at room temperature with a dose of 5 and $8 \mathrm{kGy}$.

2.2. Dielectric Studies. These studies were carried out using a Hioki LCR Impedance Analyser (model 3532-50) in the frequency range of $100 \mathrm{KHz}$ to $5 \mathrm{MHz}$, at room temperature. The samples were inserted between two copper plates of the same diameter to form a capacitor in a homemade dielectric cell whose fabrication details are reported elsewhere [13].

\section{Results and Discussion}

Figure 1 shows the XRD patterns of nano- $\mathrm{ZnO}$ crystals. The broadening in the XRD peaks reveals the nanocrystalline nature of the particles. The FTIR spectra of $\mathrm{ZnO}$ powder heat treated at $550^{\circ} \mathrm{C}$ are illustrated in Figure 2. IR spectra of $\mathrm{ZnO}$ powder heat treated at $550^{\circ} \mathrm{C}$ show bands near $1517 \mathrm{~cm}^{-1}$ (C=O stretching mode) and $2339 \mathrm{~cm}^{-1}$ (due to the adsorption of $\mathrm{CO}_{2}$ from atmosphere on the metallic cation) and a band at $500 \mathrm{~cm}^{-1}(\mathrm{Zn}-\mathrm{O})$. The scanning electron image of nanocrystalline $\mathrm{ZnO}$ powder is shown in Figure 3. The $\mathrm{ZnO}$ powder with spherical shape and particle size around $40 \mathrm{~nm}$ is observed from the SEM. The FTIR spectra of $\mathrm{ZnO}$ nanoparticles and LDPE/ZnO nanocomposites are depicted in Figures 4 and 5. The enhancement of peaks with addition of $\mathrm{ZnO}$ nanoparticles is clearly noticed in Figure 5. The dielectric studies revealed both the influence of the filler content and the effect of the electron beam irradiation on

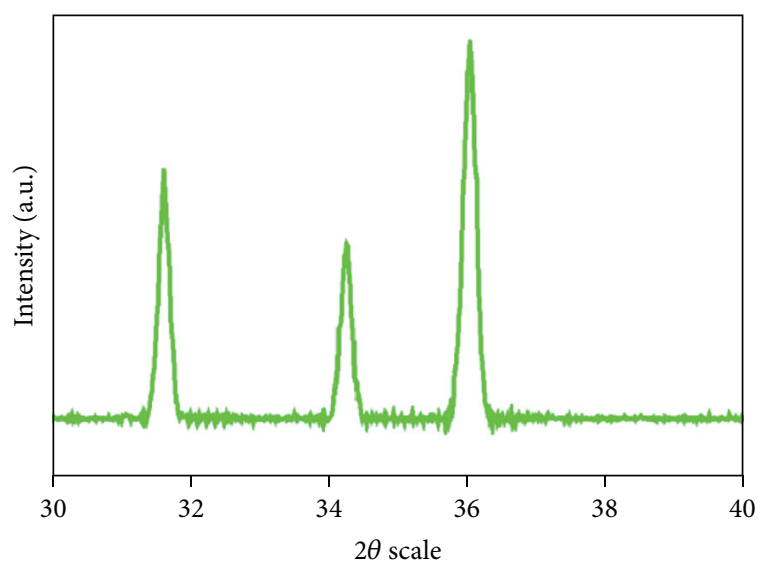

FIGURE 1: It shows the XRD pattern of $\mathrm{ZnO}$ nanoparticles.



FIGURE 2: FTIR spectra of $\mathrm{ZnO}$ nanoparticles.

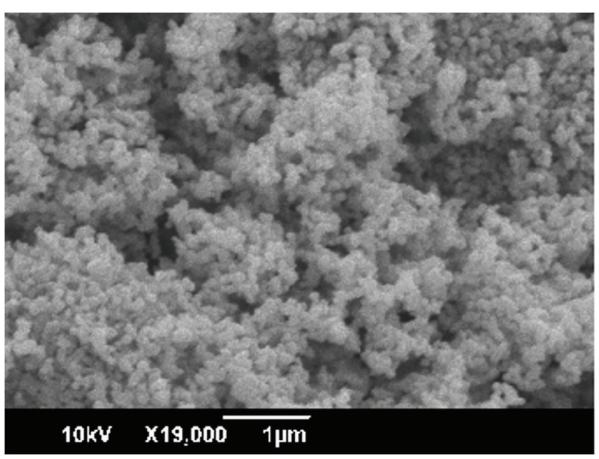

FIgURE 3: SEM images of $\mathrm{ZnO}$ nanoparticles.

the dielectric properties. The influence of the filler content (Figure 6 SEM images of nano-ZnO-LDPE composites showing uniform distribution of particles) on the real part (dielectric constant) and the complex relative permittivity (dielectric loss) of the irradiated and unirradiated samples is depicted in Figures 7 and 8. From the results shown in Figure 7, it can be observed that frequency dependence of both unirradiated and irradiated samples is alike. It can also 


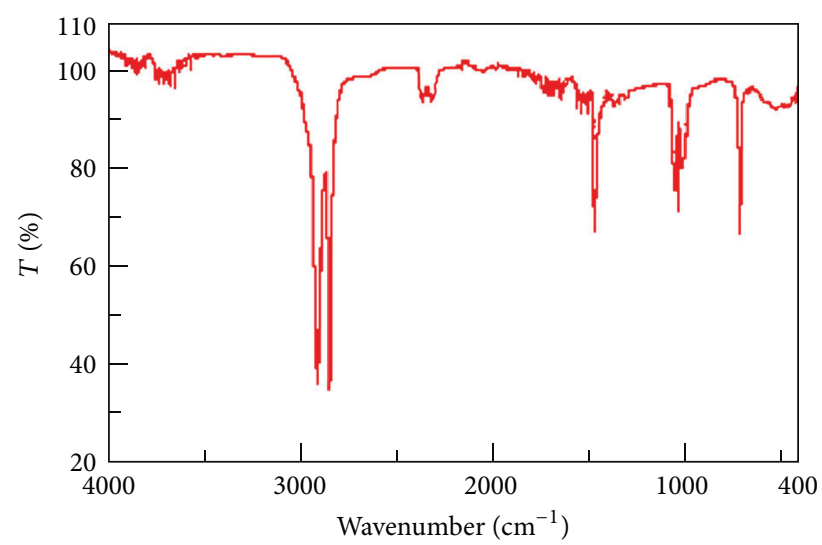

FIGURE 4: FTIR spectra of LDPE.

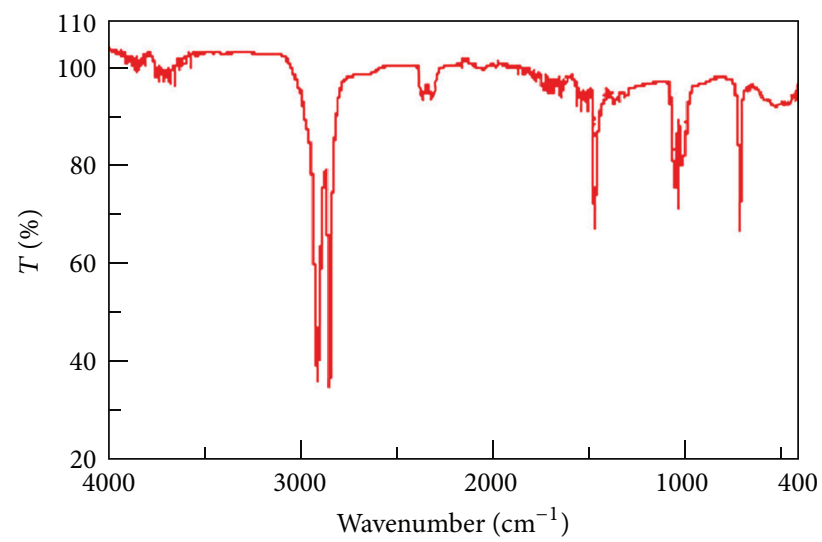

FIGURE 5: FTIR spectra of nano-ZnO-LDPE composites.

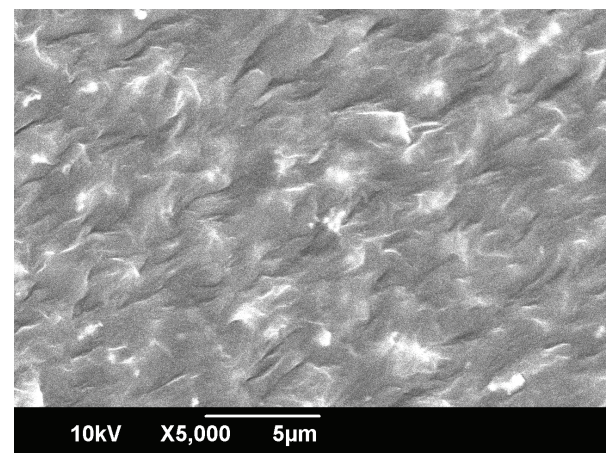

FIGURE 6: SEM images of nano-ZnO-LDPE composites showing uniform distribution of particles.

be seen that the dielectric behavior of composites is dependent upon the concentration of fillers. The dielectric constant of LDPE/ZnO nanocomposite with $8 \mathrm{wt}$.\% was found to be higher than $4 \mathrm{wt} . \%$ and $2 \mathrm{wt} . \%$. In the case of low content of nanofiller ( $2 \mathrm{wt} . \%)$, the presence of free radicals appeared in low quantity. During irradiation at $5 \mathrm{kGy}$ and $8 \mathrm{kGy}$, dielectric constant was found to be slightly decreasing when irradiation dose increased. Higher nanofiller concentration led to an intensification of the interaction processes between

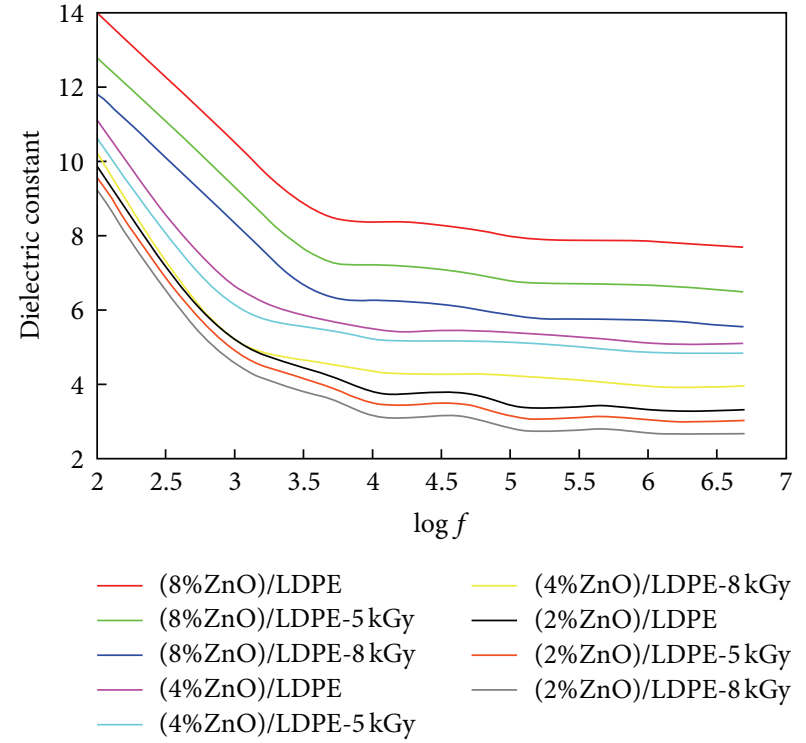

Figure 7: It shows the variation of $\log f$ with dielectric constant.

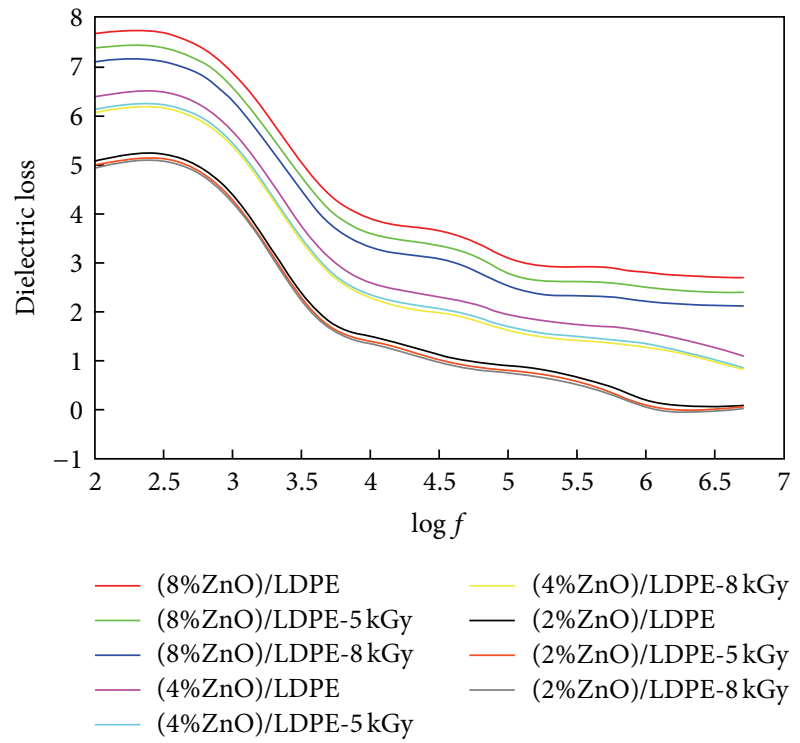

Figure 8: It shows the variation of $\log f$ with dielectric loss.

filler and polymer matrix, where radicals were formed as a consequence of high energy exposure $[14,15]$. Thus, in the case of 4 wt. $\%$ and 8 wt.\% filler levels, irradiated samples show a significant decrease with respect to those for unirradiated samples. In all the cases, dielectric constant decreases with increase in the irradiation dosage.

The influence of the filler content on the dielectric loss of the irradiated and unirradiated samples can be seen in Figure 8 in the frequency range of $100 \mathrm{KHz}$ to $5 \mathrm{MHz}$, at room temperature. As for the irradiation effect on the loss factor in the studied samples, it is similar to that of the dielectric constant. Thus, from the results shown in Figure 8, it is noticed that an improvement of the dielectric losses can be obtained at different irradiation doses depending on the filler content. 
Ciuprina et al. examined the effects of gamma radiation on dielectric properties of LDPE- $\mathrm{Al}_{2} \mathrm{O}_{3}$ nanocomposites and our results have correlation with their findings [16]. In the nanocomposites with $2 \mathrm{wt} \%$ nano- $\mathrm{ZnO}$, a dose of $8 \mathrm{kGy}$ is enough to determine an important decrease of the dielectric loss values than for the unirradiated samples. Thus, addition of $\mathrm{ZnO}$ in LDPE and electron irradiation could be a solution for improving the dielectric performances needed for better electrical energy storage dielectrics and interfaces.

\section{Conclusion}

The influence of electron radiation doses on dielectric properties was studied for LDPE/ZnO composites at different concentration. The dielectric constant and dielectric loss values were determined by dielectric spectroscopy over a frequency range of $100 \mathrm{KHz}-5 \mathrm{MHz}$ for both irradiated and unirradiated samples. Both dielectric constant and dielectric loss were found to be increased with increasing the filler concentration and decreased with increasing the irradiation rate. It was found that the dielectric properties vary with filler concentration and irradiation. By changing the filler concentration and irradiation dosage, we can tune the dielectric parameters to the desired value. This finding permits the fabrication of electronic and optoelectronic devices with improved characteristics.

\section{Conflict of Interests}

The authors declare that they have no conflict of interests.

\section{Acknowledgments}

The authors thank Dr. Ganesh Sanjeev, Microtron Centre, Department of Studies in Physics, Mangalore University, Mangalagangotri, for electron irradiation and Professor Joby Mathew, Department of English, St. Thomas College Pala, for language editing.

\section{References}

[1] S. Aslanzadeh, R. S. Rahbar, and M. Nazi, "Accelerating role of clay in photo-oxidation of polypropylene/clay multifilament yarns," Chinese Journal of Polymer Science, vol. 32, no. 5, pp. 609-619, 2014.

[2] M. J. Cadek, J. N. Coleman, V. Barron, K. Hedicke, and W. J. Blau, "Morphological and mechanical properties of carbonnanotube-reinforced semicrystalline and amorphous polymer composites," Applied Physics Letters, vol. 81, no. 27, pp. 51235125, 2002.

[3] F. Du, R. C. Scogna, W. Zhou, S. Brand, J. E. Fischer, and K. I. Winey, "Nanotube networks in polymer nanocomposites: rheology and electrical conductivity," Macromolecules, vol. 37, no. 24, pp. 9048-9055, 2004.

[4] D. E. Hill, Y. Lin, A. M. Rao, L. F. Allard, and Y.-P. Sun, "Functionalization of carbon nanotubes with polystyrene," Macromolecules, vol. 35, no. 25, pp. 9466-9471, 2002.

[5] Z. M. Dang, Y. H. Zhang, and S. C. Tjong, "Dependence of dielectric behavior on the physical property of fillers in the polymer-matrix composites," Synthetic Metals, vol. 146, no. 1, pp. 79-84, 2004.

[6] H. Zois, Y. P. Mamunya, and L. Apekis, "Structure and dielectric properties of a thermoplastic blend containing dispersed metal," Macromolecular Symposia, vol. 198, pp. 461-472, 2003.

[7] J. I. Hong, P. Winberg, L. S. Schadler, and R. W. Siegel, "Dielectric properties of zinc oxide/low density polyethylene nanocomposites," Materials Letters, vol. 59, no. 4, pp. 473-476, 2005.

[8] B. H. Schneider, E. L. Dickinson, M. D. Vach, J. V. Hoijer, and L. V. Howard, "Highly sensitive optical chip immunoassays in human serum," Biosensors and Bioelectronics, vol. 15, no. 1-2, pp. $13-22,2000$.

[9] M. S. Khalil and A. Gastli, "Investigation of the dependence of DC insulation resistivity of ultra-clean polyethylene on temperature and electric field," IEEE Transactions on Power Delivery, vol. 14, no. 3, pp. 699-704, 1999.

[10] M. Roy, J. K. Nelson, R. K. MacCrone et al., "Polymer nanocomposite dielectrics-the role of the interface," IEEE Transactions on Dielectrics and Electrical Insulation, vol. 12, no. 4, pp. 629642, 2005.

[11] A. Singh, "Irradiation of polyethylene: some aspects of crosslinking and oxidative degradation," Radiation Physics and Chemistry, vol. 56, no. 4, pp. 375-380, 1999.

[12] A. A. Basfar, M. M. Abdel-Aziz, and S. Mofti, "Accelerated aging and stabilization of radiation-vulcanized EPDM rubber," Radiation Physics and Chemistry, vol. 57, no. 3-6, pp. 405-409, 2000.

[13] E. M. Abdul Jamal, P. A. Joy, P. Kurian, and M. R. Anantharaman, "Synthesis of nickel-rubber nanocomposites and evaluation of their dielectric properties," Materials Science and Engineering: B, vol. 156, no. 1-3, pp. 24-31, 2009.

[14] S. Singha and M. J. Thomas, "Permittivity and tan delta characteristics of epoxy nanocomposites in the frequency range of $1 \mathrm{MHz}-1 \mathrm{GHz}$," IEEE Transactions on Dielectrics and Electrical Insulation, vol. 15, no. 1, pp. 2-11, 2008.

[15] C. Zhang and G. C. Stevens, "The dielectric response of polar and non-polar nanodielectrics," IEEE Transactions on Dielectrics and Electrical Insulation, vol. 15, no. 2, pp. 606-617, 2008.

[16] F. Ciuprina, T. Zaharescu, and I. Pleşa, "Effects of $\gamma$-radiation on dielectric properties of $\mathrm{LDPE}-\mathrm{Al}_{2} \mathrm{O}_{3}$ nanocomposites," Radiation Physics and Chemistry, vol. 84, pp. 145-150, 2013. 

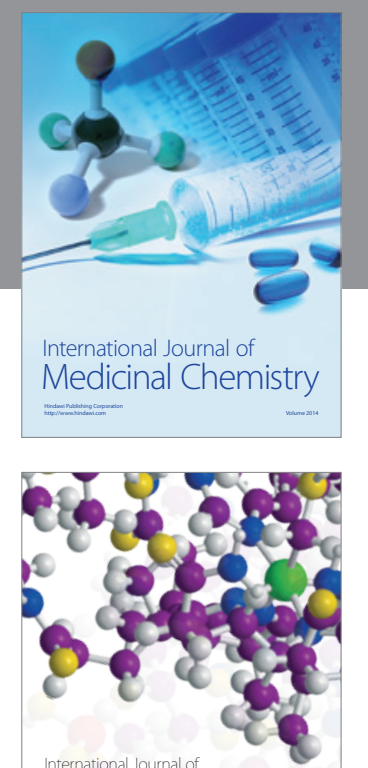

\section{Carbohydrate} Chemistry

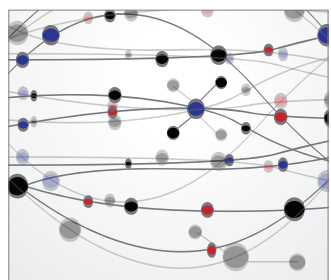

The Scientific World Journal
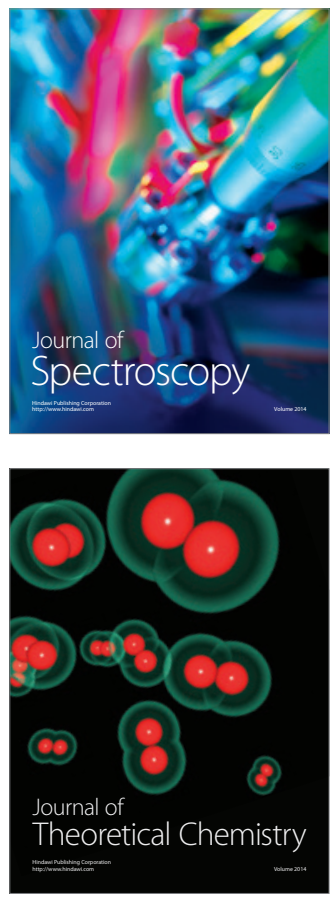
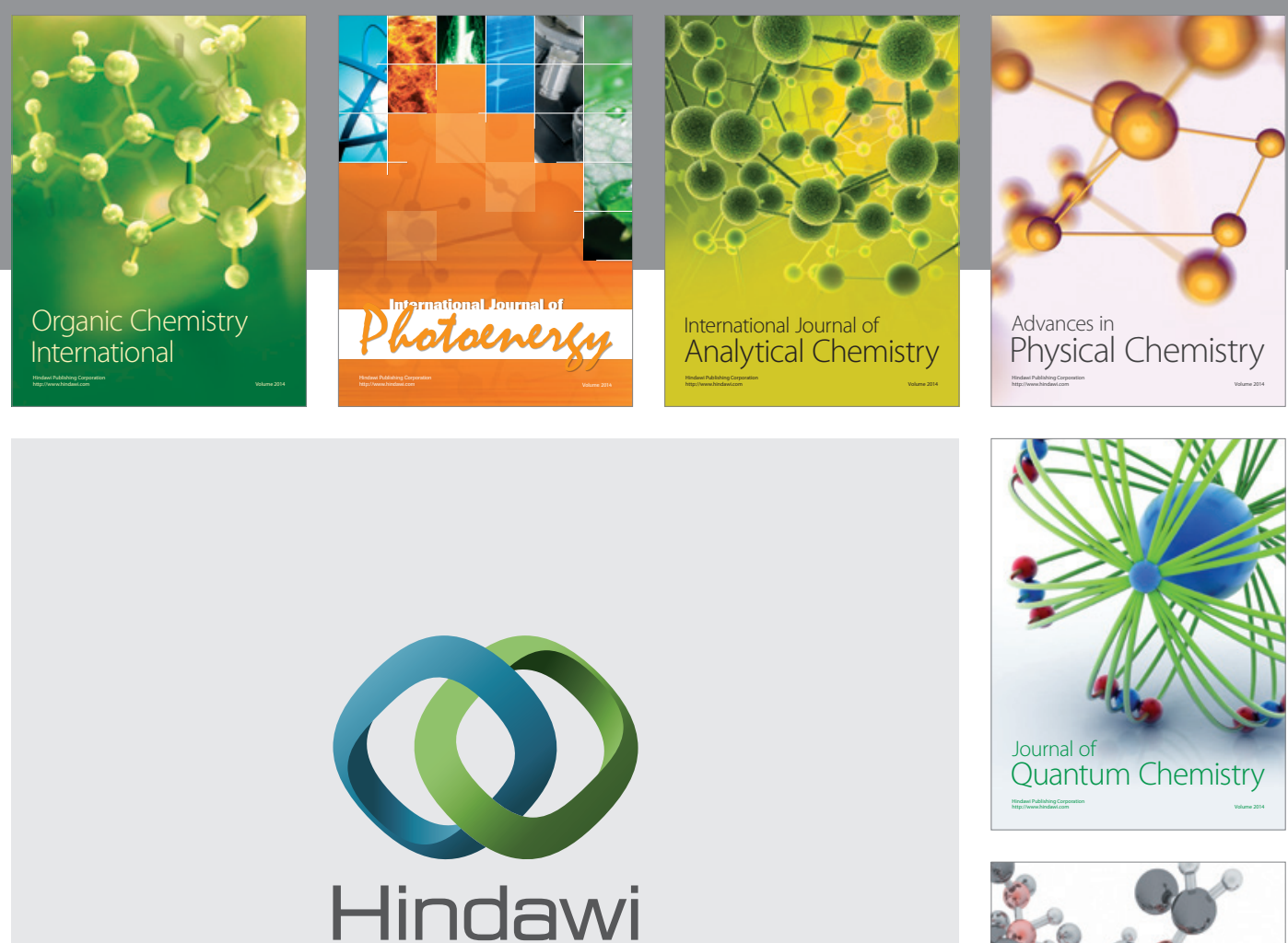

Submit your manuscripts at

http://www.hindawi.com

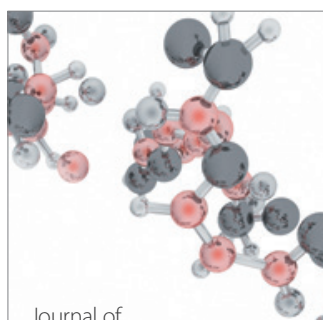

Analytical Methods

in Chemistry

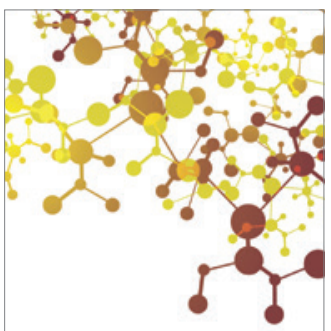

Journal of

Applied Chemistry

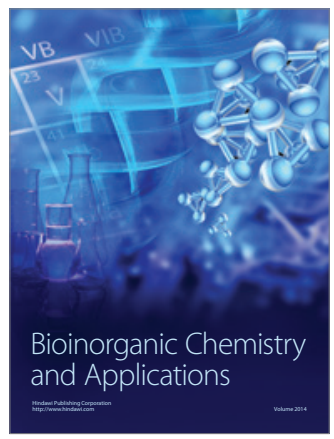

Inorganic Chemistry
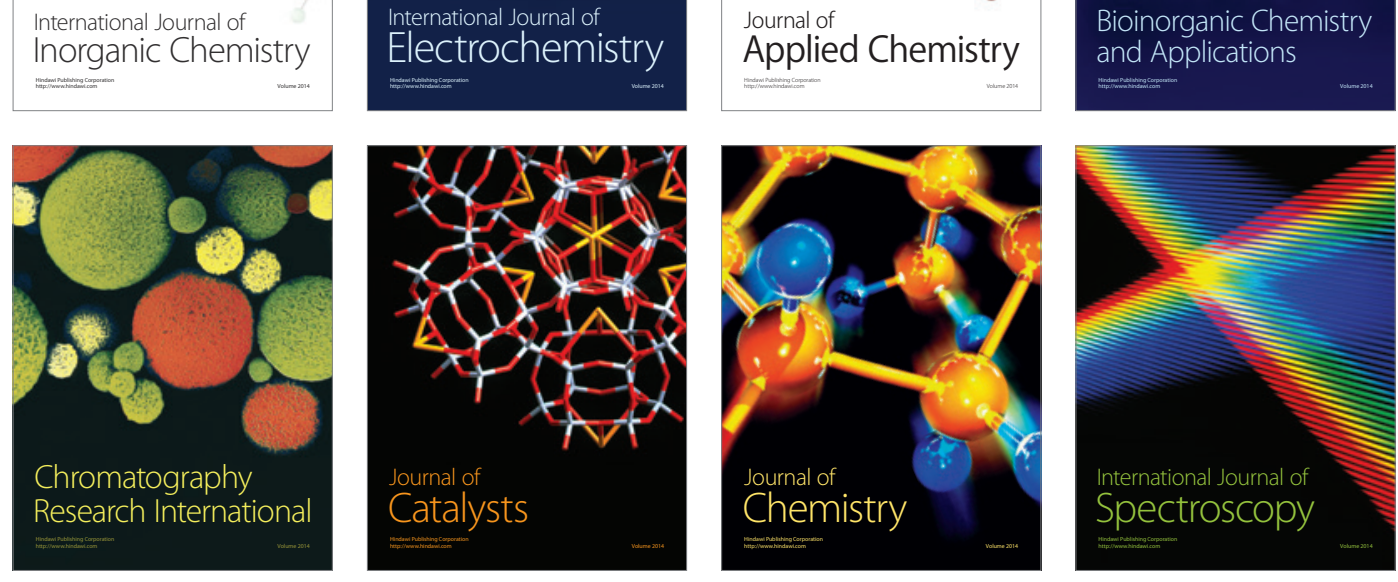